\title{
Distribuição da altura uterina ao longo da gestação em uma coorte brasileira - comparação com a curva de referência do Centro Latino-Americano de Perinatologia
}

\author{
Distribution of uterine height along gestation in a Brazilian cohort \\ - comparison with the reference carue of the Latin-American Center of Perinatology
}

Roberto Eduardo Bittar

A partir de 1953, com o estudo de Rumbolz e McGoogan ${ }^{1}$, a medida seriada da altura uterina (AU), com a fita métrica, passou a ser rotina nas consultas de pré-natal. Tanto o American College of Obstetricians and Gynecologists (ACOG) ${ }^{2}$ como o Royal College of Obstetricians and Gynaecologists $(\mathrm{RCOG})^{3}$, em suas últimas publicações, recomendam esta prática. O uso desta técnica e a utilização de uma curva de crescimento da AU em função da idade gestacional (IG) permitem a detecção do crescimento fetal normal e o rastreamento de seus desvios. Embora a ultra-sonografia, quando utilizada com os mesmos objetivos, ofereça maior precisão, deve ser reservada para a confirmação dos resultados, pois envolve maior custo e necessita de profissionais capacitados.

A publicação do ACOG cita que a medida da AU entre 32 e 34 semanas de gestação revela sensibilidade (S) entre 70 e $85 \%$ e especificidade (E) de $96 \%$ para a detecção da restrição do crescimento fetal (RCF), ao passo que o RCOG cita valores de 27 e 88\%, respectivamente. Quando analisado o valor preditivo positivo, ou seja, a probabilidade de RCF com AU inferior ao esperado pela IG, esta variou de $60-70 \%$ segundo o ACOG e foi de 20\%, segundo o RCOG. Estas grandes diferenças podem ser atribuídas a não-uniformidade quanto a: características populacionais, cálculos da IG, critérios para a definição de $\mathrm{RCF}$, curvas de normalidades utilizadas e técnica de medida da AU. Portanto, para a interpretação correta de resultados de qualquer estudo sobre o tema, todos estes aspectos têm que ser considerados.

$\mathrm{O}$ artigo de Oppermann et $\mathrm{al} .{ }^{4}$ avalia a medida da AU em 3539 gestantes, pertencentes a um estudo de coorte, em serviços de atendimento pré-natal do SUS, em seis cidades brasileiras, com o intuito de comparar com a curva de referência do Centro Latino-Americano de Perinatologia (CLAP). A confirmação da IG foi estabelecida pela ultra-sonografia com até 26 semanas (n=2782) ou após 26 semanas para as restantes. A curva utilizada para o diagnóstico neonatal - adequados (AIG), pequenos (PIG) ou grandes (GIG) - não foi citada e foram incluídas gestações sem confirmação ultra-sonográfica da idade gestacional. É desejável e interessante que o estudo tenha como objetivo comparar as medidas de AU obtidas com as curvas do CLAP, adotadas pelo Ministério da Saúde. As curvas do CLAP originaram-se no estudo de Fescina et al. ${ }^{5}$, em 1984, quando foram avaliadas 163 gestantes. Foram considerados parâmetros de normalidade para o crescimento uterino o percentil 10, para o limite inferior, e o percentil 90, para o limite superior. O estudo demonstrou $\mathrm{S}=52 \%$ e $\mathrm{E}=92 \%$ para o diagnóstico de $\mathrm{RCF}$ e $\mathrm{S}=92 \%$ e $\mathrm{E}=72 \%$ para o diagnóstico de macrossomia. Deve ser destacado que para um método de rastreamento ser considerado bom deve ter alta sensibilidade. Como pode ser observado, no estudo Fescina et al. ${ }^{5}$ a sensibilidade para a detecção da RCF mostrou-se baixa, porém superior ao de Oppermann et al. ${ }^{4}(\mathrm{~S}=29 \%$ na $32^{a}$ semana). Por outro lado, para a identificação dos macrossômicos na $32^{a}$ semana, a sensibilidade deste último estudo foi muito baixa $(\mathrm{S}=21 \%)$ e a especificidade alta $(\mathrm{E}=93 \%)$, quando comparadas com o estudo de Fescina et al. ${ }^{5}, 87$ e 46\%, respectivamente. Dessa maneira, Oppermann et al. ${ }^{4}$ concluem que os percentis 10 e 90 das curvas do CLAP são muito diferentes daqueles obtidos em seus resultados e que, portanto, as últimas não refletem o padrão de crescimento uterino das gestantes brasileiras. Pode até ser que a curva de Fescina et $a l .{ }^{5}$ não seja a mais adequada para o acompanhamento do crescimento fetal das gestantes brasileiras, como já sugerido em outro estudo realizado em nosso meio ${ }^{6}$. No entanto, as diferenças metodológicas entre os dois estudos e a falta de controle rigoroso de alguns

Professor Associado do Departamento de Obstetrícia e Ginecologia

Faculdade de Medicina da Universidade de São Paulo - USP - São Paulo (SP), Brasil. 
fatores que influenciam nos resultados não permitem que se chegue a esta conclusão. A IG neste estudo foi determinada tardiamente pela ultra-sonografia. Já no estudo de Fescina et al. ${ }^{5}$, o cálculo da IG foi apenas baseado na data da última menstruação (DUM). O mais apropriado seria basear-se na DUM correspondente à ultra-sonografia realizada até a $12^{a}$ semana. Na ausência da DUM, o correto seria considerarem-se pelo menos duas ultra-sonografias compativeis até a $20^{\mathrm{a}}$ semana. Sem estes cuidados é impossivel datar corretamente a gestação e o diagnóstico de adequação antenatal e pós-natal fica prejudicado. A avaliação neonatal da idade gestacional que é feita em geral com $24 \mathrm{~h}$ de vida (método de Capurro, por exemplo) apresenta maior erro quando comparada à ultra-sonografia em IG precoce. O diagnóstico definitivo de AIG, PIG ou GIG é dado pela curva de crescimento adotada pelo berçário. No estudo em análise não se fez referência à curva adotada. Para interpretar os valores obtidos de AU, além dos aspectos considerados, deve-se considerar a técnica de medida utilizada. No estudo não se destacou qual foi a técnica utilizada - a que é realizada da sínfise púbica ao fundo uterino, fixando-se a fita métrica com a face cubital da mão, aquela em que a leitura é realizada com a fita entre os dedos indicador e médio ou a técnica do arco, com a fita fixada entre os dedos polegar e indicador? Foi considerado um número mínimo de medidas (consultas)? As gestantes esvaziavam a bexiga antes do procedimento de medida da AU? Como era a fita métrica - flexivel ou inelástica? Além disso, o fato de a medida da AU ter sido realizada por vários observadores é um dos fatores que pode ter determinado grande variação nas medidas. Tomou-se alguma medida para diminuir a variabilidade intra-observador?

Como vários outros estudos já demonstraram, em virtude dos inúmeros fatores epidemiológicos que influenciam o crescimento fetal, cada região deve ter a sua própria curva de AU. No entanto, na construção destas curvas os fatores acima descritos que podem levar a erros de interpretação devem ser rigorosamente controlados.

\section{Referências}

1. Rumbolz WL, McGoogan LS. Placental insufficiency and the small undernourished full-term infant. Obstet Gynecol. 1953;1(3):294-301.

2. American College of Obstetricians and Gynecologists. Intrauterine growth restriction. Washington D.C: ACOG; 2000. (ACOG Practice Bulletin, 12).

3. Royal College of Obstetricians and Gynaecologists. The Investigation and management of the small-for-gestationalage fetus. London: RCOG; 2002. (Guideline, 31).

4. Oppermann MLR, Duncan BB, Mengue SS, Ramos JGL, Serruya SJ, Schmidt MI. Distribuição da altura uterina ao longo da gestação em uma corte brasileira - comparação com a curva de referência do Centro Latino-Americano de Perinatologia (CLAP). Rev Bras Ginecol Obstet. 2006;28(9):513-22.

5. Fescina RH, Quevedo C, Martell M, Nieto F, Schwarcz R. Altura uterina como método para predecir el crescimiento fetal. Bol Oficina Sanit Panam. 1984;96(5):377-86.

6. Freire DMC, Paiva CSM, Coelho EAC, Cecatti JG. Curva da altura uterina por idade gestacional em gestantes de baixo risco. Rev Bras Ginecol Obstet. 2006;28(1):3-9.

\section{Comentários do autor}

O Conselho Editorial da RBGO acertou ao reconhecer a importância do tema abordado em nosso artigo $^{1}$, redigindo um comentário editorial a respeito no mesmo fascículo². Ao fazê-lo, toma como referência o artigo de Chauhan e Magann ${ }^{3}$, publicado recentemente, que compara as propriedades diagnósticas da altura uterina na detecção da restrição do crescimento intra-uterino obtidas no estudo do American College of Obstetricians and Gynecologists (ACOG) e no do Royal College of Obstetricians and Gynaecologists (RCOG). Os resultados muito díspares desses dois estudos ilustram a problemática da medida rotineira da altura uterina usada no cuidado pré-natal: considerando uma probabilidade pré-teste de $10 \%$ para restrição do crescimento intra-uterino, as probabilidades pós-teste positivo (equivalentes aos valores preditivos positivos) foram de $66-70 \%$ (ACOG) e 20\% (RCOG).

O comentário editorial analisa criticamente nosso artigo e o estudo de Fescina et al. ${ }^{4}$, que 